\title{
Desenvolvimento dos Parâmetros do Processo de Soldagem por Atrito com Pino Não Consumível para o Aço de Alta Resistência e Baixa Liga ISO 3183 X80Mª
}

\author{
Tahiana F. C. Hermenegildo ${ }^{1}$, Ana Carla S. Silva², Edwar A. Torres ${ }^{3}$, Tiago F. A. Santos ${ }^{1}$, Antonio J. Ramirez \\ ${ }^{1}$ Universidade Federal de Pernambuco - UFPE, Departamento de Engenharia Mecânica, Recife, PE, Brasil. \\ ${ }^{2}$ Universidade Federal de Pernambuco - UFPE, Programa de Pós-graduação em Engenharia Mecânica, Recife, PE, Brasil. \\ ${ }^{3}$ Universidad de Antioquia, Departamento de Ingeniería Mecánica, Medellín, AN, Colombia. \\ ${ }^{4}$ The Ohio State University, Department of Materials Science and Engineering, Columbus, USA.
}

Recebido: 22 Mar., 2017

Aceito: 12 Jun., 2017

E-mail: tfchermenegildo@gmail.com $(\mathrm{TFCH})$ a Contribuição para XLII CONSOLDA Congresso Nacional de Soldagem.

Este é um artigo publicado em acesso aberto (Open Access) sob a licença Creative Commons Attribution Non-Commercial, que permite uso, distribuição e reprodução em qualquer meio, sem restriçōes desde que sem fins comerciais e que 0 trabalho original seja corretamente citado.
Resumo: Sabe-se que as velocidades de soldagem e rotacional, força axial, ângulo de inclinação e desenho da ferramenta são as principais variáveis de entrada independentes, que são utilizadas para controlar o processo de soldagem por atrito com pino não consumível, e que a taxa de geração de calor, taxa de resfriamento, força na direção de soldagem e o torque são as variáveis de resposta, que irão influenciar na evolução microestrutural e desempenho mecânico da junta soldada. Neste trabalho foi feito um estudo do comportamento destas variáveis visando o desenvolvimento de parâmetros para o aço API 5 L X80 (ISO 3183 X80M). Para tanto, chapas com $12 \mathrm{~mm}$ de espessura, foram soldadas através de dois passes, utilizando ferramenta de nitreto de boro cúbico policristalino. Observou-se que, mantendo-se a velocidade de soldagem constante, o aumento da velocidade rotacional e /ou da força axial, tende a reduzir as forças reativas e o torque atuantes durante o processo pelo aumento da taxa de geração de calor. Por outro lado, mantendo-se essas variáveis constantes, o aumento da velocidade de soldagem tende a aumentar as forças e o torque, uma vez que para o aço, este parâmeto desempenha um papel significativo na taxa de geração de calor durante o processo.

Palavras-chave: Variáveis de processo; Soldagem por atrito com pino não consumível; Desempenho mecânico.

\section{Development of Friction Stir Welding Process Parameters for the High Strength Low Alloy Steel ISO 3183 X80M}

\begin{abstract}
It is known that welding and rotational speeds, axial force, the inclination angle, and the tool design are the main independent input variables which are used to control the process of friction stir welding, and the heat generation rate and cooling, force in the welding direction and torque are the response variables that will change the microstructural evolution and mechanical performance of the welded joint. In this work, the behavior of these input and response variables aiming the development of friction stir welding process applied to steel API 5L X80 (ISO 3183 X80M) steel were studied. For this purpose, plates with $12 \mathrm{~mm}$ thick were welded by two passes using polycrystalline cubic bore nitrite tool. It was observed that, while keeping the welding speed constant, an increase in spindle speed and /or axial force, tends to reduce the reactive forces and the torque acting during the process by increasing of the heat generation rate. Otherwise, keeping spindle speed and axial force constants, the welding speed rising the forces and torque, allowing the welding speed plays a significant role in the heat generation rate during the process.
\end{abstract}

Key-words: Process variables; Friction stir welding; Mechanical performance.

\section{Introdução}

Este estudo teve como base o aço ARBL ISO 3183 X80M, produzido no Brasil pelo processo termomecânico TMCP (Thermomechanically Controlled Processing), sem resfriamento acelerado, microligado com nióbio, vanádio e titânio para refinamento de grão e endurecimento por precipitação [1,2]. O aço comercial ISO 3183 X80M, equivalente ao aço (API) $5 \mathrm{~L} \mathrm{X80,} \mathrm{tem} \mathrm{uma} \mathrm{microestrutura} \mathrm{composta} \mathrm{por} \mathrm{ferrita} \mathrm{poligonal,} \mathrm{bainita} \mathrm{e}$ perlita degenerada o que lhe garante propriedades mecânicas elevadas, boa tenacidade e soldabilidade [3]. Esta combinação de propriedades tornou mais relevante a classe do aço X80 nas operações de transporte de óleo e gás, o que vem aumentando a demanda por pesquisas visando o desenvolvimento de processos de soldagem mais eficientes. 
O processo de Soldagem por Atrito com Pino Não-Consumível (SAPNC) vem sendo aplicado para unir vários materiais, incluindo alumínio, magnésio, chumbo, zinco, e ligas de cobre. Nos últimos anos, a aplicação deste processo para soldagem de ligas de alta temperatura de fusão como aços, aços inoxidáveis e ligas de titânio tem atraído cada vez mais a atenção do setor aeroespacial, construção naval e petroquímica [4-6]. No entanto, ainda é necessária uma compreensão mais abrangente do processo, devido ao elevado custo tanto do equipamento quanto das ferramentas utilizadas para soldagem de aços e outras ligas metálicas de alta temperatura de fusão.

O processo de SAPNC envolve um complexo movimento do material ao redor do pino da ferramenta associado à deformação plástica severa. Parâmetros de soldagem, geometria da ferramenta e projeto da junta exercem um papel importante no escoamento do material e na distribuição de temperatura que, consequentemente, irão influenciar na evolução microestrutural e no desempenho mecânico da junta soldada [7].

Os principais parâmetros de processo incluem a velocidade de rotação da ferramenta (VR, rpm), a força axial exercida pela ferramenta sobre a junta e a velocidade de soldagem (VS, $\mathrm{mm} / \mathrm{min}$ ). As reações mais relevantes geradas nesse processo são o torque, a força na direção da soldagem $(\mathrm{Fx})$, e na direção transversal à junta soldada. Uma inclinação adequada da ferramenta rumo à direção da junta a ser soldada garante que o ombro da ferramenta contenha o material plastificado, redirecionando-o para baixo e promovendo assim um escoamento adequado do material. Na prática, os parâmetros de soldagem devem ser otimizados levando-se em conta o tipo e a espessura dos materiais a serem soldados e o tipo de junta a ser produzida [8].

Dentro deste contexto, neste trabalho foi avaliado o comportamento das variáveis de entrada, velocidades de soldagem e rotacional e da força axial sobre as variáveis de resposta, visando o desenvolvimento do processo de SAPNC para o aço ISO 3183 X80M (API 5L X80) de fabricação nacional.

\section{Materiais e Métodos}

Neste trabalho foi estudado o aço ISO 3183 X80M de baixo carbono, microligado ao $\mathrm{Nb}, \mathrm{V}$ e Ti, conforme mostra a Tabela 1, fabricado pelo processo termomecânico TMCP, sem resfriamento acelerado e laminado em chapa até a espessura de $19 \mathrm{~mm}$. A Tabela 2 mostra as propriedades mecânicas segundo fabricante.

Tabela 1. Composição química (wt\%) do aço ISO 3183 X80M.

\begin{tabular}{|c|c|c|c|c|c|c|c|c|}
\hline C & $\mathrm{Mn}$ & Si & $\mathbf{P}$ & S & Al & $\mathrm{Nb}$ & v & \multirow{4}{*}{$\begin{array}{l}\text { Carbono equivalente } \\
(C E)^{*} 0,17\end{array}$} \\
\hline 0,05 & 1,76 & 0,17 & 0,016 & 0,002 & 0,035 & 0,066 & 0,025 & \\
\hline $\mathrm{Ti}$ & $\mathrm{Cu}$ & $\mathbf{N i}$ & $\mathrm{Cr}$ & Mo & $\mathbf{N}$ & B & $\mathrm{Ca}$ & \\
\hline 0,016 & 0,02 & 0,02 & 0,15 & 0,20 & 0,0059 & 0,003 & 0,003 & \\
\hline
\end{tabular}

*CE, segundo critério da norma API 1104.

Tabela 2. Propriedades mecânicas do material de base, segundo fabricante do aço.

\begin{tabular}{cccc}
\hline $\begin{array}{c}\text { Tensão limite de } \\
\text { Escoamento } \sigma_{\mathrm{e}}(\mathrm{MPa})\end{array}$ & $\begin{array}{c}\text { Tensão limite de Resistência } \\
\text { à tração } \sigma_{\mathrm{LRT}}(\mathrm{MPa})\end{array}$ & Relação $\left(\sigma_{\mathrm{e}}\right) /\left(\sigma_{\mathrm{LRT}}\right)$ & Alongamento $(\%)$ \\
568 & 686 & 83 & 44 \\
\hline
\end{tabular}

Chapas de $500 \mathrm{~mm}$ de comprimento $\times 90,0 \mathrm{~mm}$ de largura $\times 19,0 \mathrm{~mm}$ de espessura foram usinadas para $12,0 \mathrm{~mm}$ de espessura com o cuidado de se manter o bandeamento das chapas no centro das mesmas, devido a limitação do comprimento do pino da ferramenta utilizado no processo de soldagem.

No processamento das juntas soldadas foram utilizadas ferramentas cerâmicas de nitreto de boro cúbico policristalino, conhecidas por PCBN, seu acrônimo em inglês, disponíveis comercialmente com pino de $6,0 \mathrm{~mm}$ de comprimento e com diâmetro do ombro de $24,0 \mathrm{~mm}$.

Para execução das juntas soldadas foi utilizada uma máquina modelo RM-2, fabricada pela "Transformation Technologies Incorporated (TTI)". (que pode ser operada utilizando dois modos de controle distinto, denominados 
Desenvolvimento dos Parâmetros do Processo de Soldagem por Atrito com Pino Não Consumível para o Aço de Alta Resistência e Baixa Liga ISO 3183 X80M

controle de posição e de força) no Laboratório Nacional de Nanotecnologia/CNPEM/MCTI. No modo "Controle de Posição" é possível controlar manualmente o deslocamento da ferramenta no eixo $Z$, determinando assim a força axial. Já no modo "Controle de Força", a máquina é configurada para operar mantendo a força axial constante, (uma vez que esta tenha sido estabelecida previamente utilizando o modo Controle de Posição), garantido assim que o processo de soldagem ocorra de maneira estável. Na Tabela 3 constam as especificações da máquina.

Tabela 3. Especificações da Máquina de SAPNC.

\begin{tabular}{ccccc}
\hline Eixo & $\begin{array}{c}\text { Força máxima } \\
(\mathbf{k N})\end{array}$ & $\begin{array}{c}\text { Velocidade máxima } \\
(\mathbf{m m} / \mathbf{m i n})\end{array}$ & $\begin{array}{c}\text { Deslocamento } \\
\text { máximo }(\mathbf{m m})\end{array}$ & Modo de Controle \\
$\mathrm{X}$ & 22,5 & 3000 & 645 & Força/ Posição \\
$\mathrm{Y}$ & 22,5 & 3000 & 260 & Posição \\
$\mathrm{Z}$ & 67,0 & 1000 & 275 & Força/ Posição \\
\hline
\end{tabular}

Inicialmente foram produzidas juntas soldadas com $100 \mathrm{~mm}$ de comprimento sobre uma única chapa, (bead-on-plate), para facilitar a determinação dos parâmetros de soldagem e avaliação do comportamento da ferramenta durante o processo. Para auxiliar na escolha dos parâmetros, foi utilizada a razão entre VS e VR denominada de passo de solda, a qual fornece um indicativo do aporte térmico durante o processo. Nesta etapa, a máquina foi configurada para ser utilizada no modo de Controle de Posição. Neste modo de operação foi determinada a força axial a ser utilizada de modo a garantir a penetração e o contato ideal entre o ombro da ferramenta e o metal de base, o qual gera o aquecimento necessário por atrito e deformação para que o material seja adequadamente plastificado.

Durante esta etapa foram selecionados os parâmetros de entrada; velocidade rotacional (VR), velocidade de soldagem (VS) e a força axial, mantendo a força na direção de soldagem $\left(F_{x}\right)$, Figura 1, abaixo de $5 \mathrm{kN}$ a fim de estender a vida útil da ferramenta. Esta limitação na escolha dos parâmetros de soldagem reduziu a janela de processo, o que dificultou a obtenção de juntas soldadas com condições termomecânicas muito diferenciadas. A Figura 2 ilustra o comportamento da força atuante na direção de soldagem $\left(F_{x}\right)$, ao longo da espessura $\left(F_{z}\right)$ e da temperatura registrada por um termopar localizado próximo à ferramenta, para todas as juntas processadas.

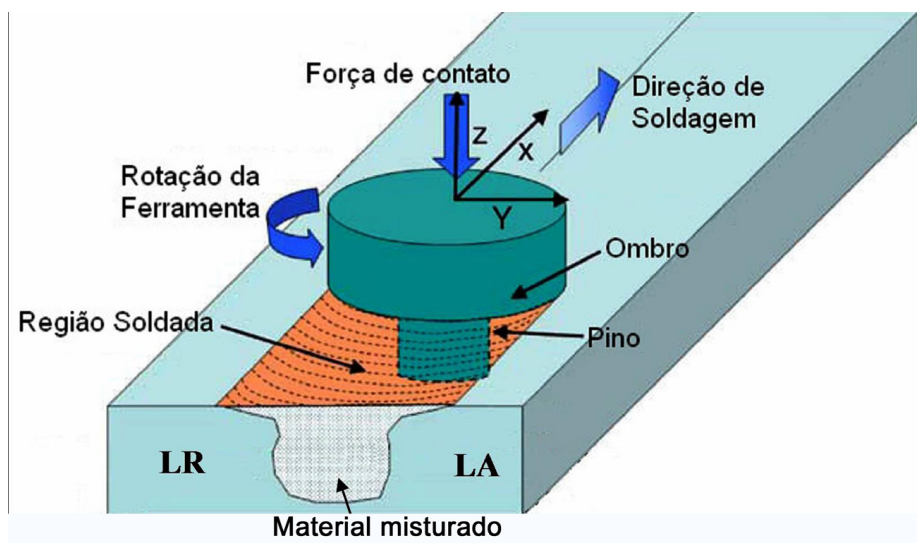

Figura 1. Esquema do processo de SAPNC. Adaptado de Gray e Pontremoli [1].

Após estas etapas, a máquina foi configurada no modo Controle de Força e uniões de topo entre duas chapas de aço, através de dois passes, sendo um em cada lado da chapa, com $380 \mathrm{~mm}$ de comprimento foram realizadas. As juntas soldadas foram feitas na direção normal à direção de laminação da chapa. Todas as juntas soldadas realizadas foram monitoradas através de uma interface de aquisição de dados instalada em um microcomputador, o que permitiu o monitoramento do torque, das forças nas direções $x, y, z$ e do ciclo térmico durante o processo de soldagem. 


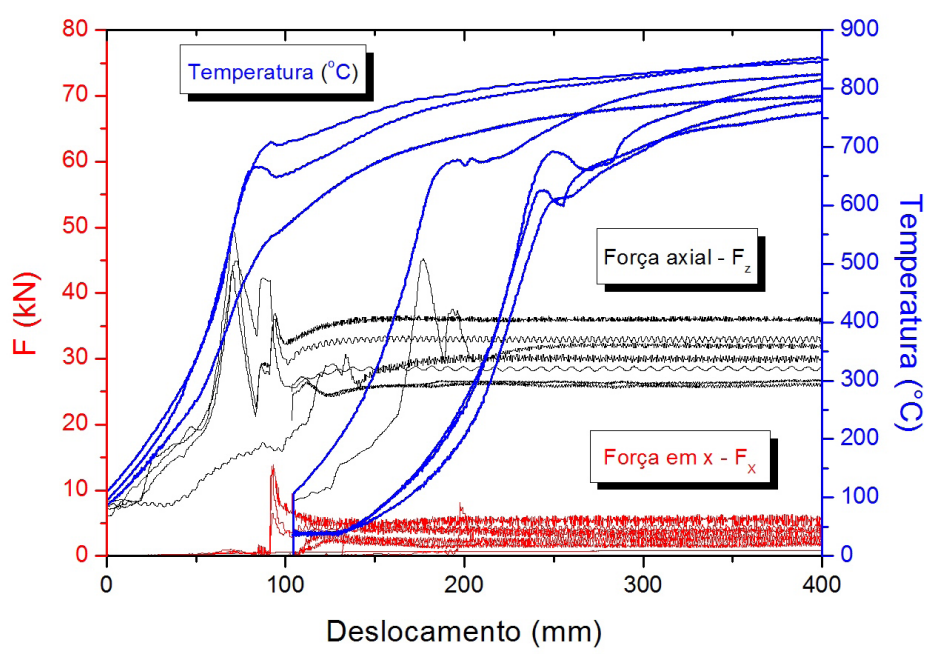

Figura 2. Evolução da força axial $\left(F_{z}\right)$, na direção de soldagem $\left(F_{x}\right)$ e da temperatura na ferramenta durante o processo de SAPNC.

Foi utilizada proteção gasosa com fluxo de argônio a fim de se evitar a degradação das ferramentas e da área soldada.

Todas as juntas soldadas foram radiografadas e submetidas ao teste de dobramento lateral e de tração segundo a norma ISO 3183 [9].

\section{Resultados e Discussão}

\subsection{Processo de soldagem}

Após diversas tentativas e a perda de algumas ferramentas, juntas soldadas normais à direção de laminação da chapa, com comprimento de $380 \mathrm{~mm}$ e largura variando entre 16,5 a $20,0 \mathrm{~mm}$ na face da junta soldada, isentas de defeitos internos e externos, foram obtidas com penetração total, mediante a soldagem em dois passes, um em cada lado da chapa, mantendo o lado de avanço (LA) do primeiro passe cruzado em relação ao do segundo passe, conforme ilustra a Figura $3 \mathrm{~b}$.

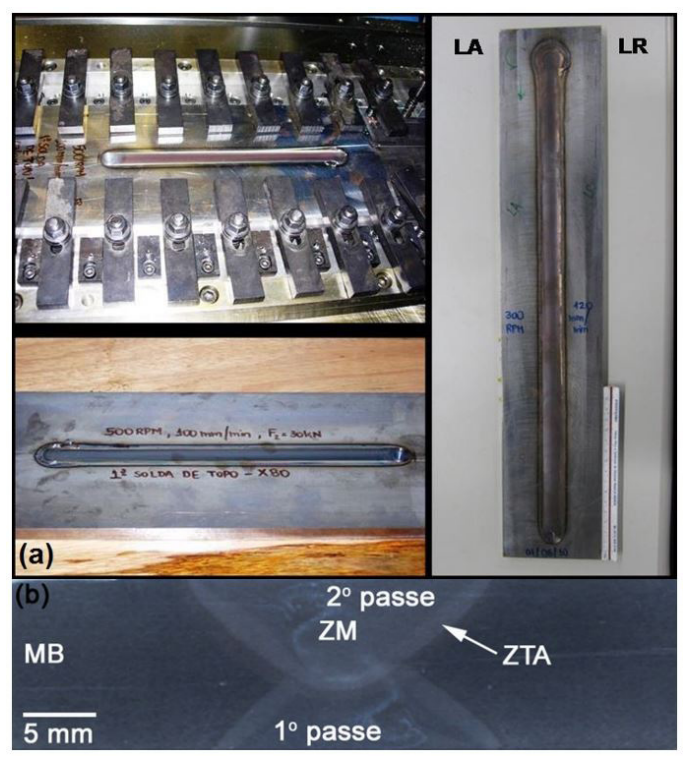

Figura 3. (a) Soldas de topo processadas mediante o processo de SAPNC; (b) macroestrutura da seção transversal da junta soldada por SAPNC em ambas as faces, superior e inferior. 
Desenvolvimento dos Parâmetros do Processo de Soldagem por Atrito com Pino Não Consumível para o Aço de Alta Resistência e Baixa Liga ISO 3183 X80M

$\mathrm{Na}$ Tabela 4, consta para as sete soldas processadas os valores registrados durante o processo de soldagem para os seguintes parâmetros: torque, força atuante na direção de soldagem $\left(F_{x}\right)$, a força axial e a temperatura máxima registrada pelo termopar localizado próximo a ferramenta de PCBN. É importante salientar que, a leitura feita pelo termopar localizado na ferramenta não pode ser comparada com a temperatura atingida na zona mistura. Porém, devido à alta condutividade térmica da ferramenta, tais valores foram utilizados para auxiliar na comparação e na escolha dos parâmetros processados para estudo.

Tabela 4. Parâmetros de soldagem registrados para as juntas soldadas.

\begin{tabular}{|c|c|c|c|c|c|c|c|}
\hline Juntas & VR-VS & $\begin{array}{c}\text { VS/VR } \\
\text { (mm/rev) }\end{array}$ & ${ }^{*} \mathrm{AT}(\mathrm{kJ} / \mathrm{mm})$ & $F_{x}(N)$ & $\begin{array}{l}\text { Força Axial } \\
\text { (N) }\end{array}$ & $\begin{array}{l}\text { Torque } \\
\text { (N.m) }\end{array}$ & $\begin{array}{c}\text { **Temperatura } \\
\text { Máxima }\left({ }^{\circ} \mathrm{C}\right)\end{array}$ \\
\hline 1 & $500-100$ & 0,20 & 1,91 & 3581 & 29778 & 61 & 900 \\
\hline 2 & $350-100$ & 0,28 & 1,98 & 3661 & 32848 & 90 & 882 \\
\hline 3 & $300-100$ & 0,33 & 1,92 & 3877 & 31893 & 102 & 864 \\
\hline 4 & $400-80$ & 0,20 & 2,16 & 2120 & 25864 & 69 & 833 \\
\hline 5 & $300-80$ & 0,26 & 2,10 & 2251 & 26352 & 88 & 780 \\
\hline 6 & $400-120$ & 0,30 & 1,71 & 3611 & 28242 & 82 & 870 \\
\hline 7 & $300-120$ & 0,40 & 1,69 & 4865 & 35798 & 108 & 763 \\
\hline
\end{tabular}

* Aporte Térmico; ** Temperatura da Ferramenta.

Sabe-se que as velocidades de soldagem e rotacional, a força axial, o ângulo de inclinação da ferramenta e o desenho da ferramenta são as principais variáveis de entrada independentes, que são utilizadas para controlar o processo de SAPNC, e que a taxa de geração de calor, taxa de resfriamento, força na direção de soldagem $\left(F_{x}\right)$ e o torque são as variáveis de resposta, dependentes destas variáveis. Como neste estudo não foi utilizado ângulo de inclinação para ferramenta e nem houve variação no desenho da mesma, foram abordados apenas os efeitos das velocidades de soldagem e rotacional e da força axial sobre as variáveis de resposta.

O efeito das velocidades de soldagem e rotacional sobre a temperatura máxima atingida pela ferramenta pode ser sumarizado pela Figura 4, na qual observa-se um aumento da temperatura máxima atingida pela ferramenta com a elevação da velocidade rotacional. Porém, era de se esperar que as juntas soldadas com VS de $80 \mathrm{~mm} / \mathrm{min}$ apresentassem temperaturas máximas superiores as demais VS. Tal inconsistência pode estar relacionada às profundidades de penetrações diferentes, a qual determina o contato do ombro da ferramenta com a superfície

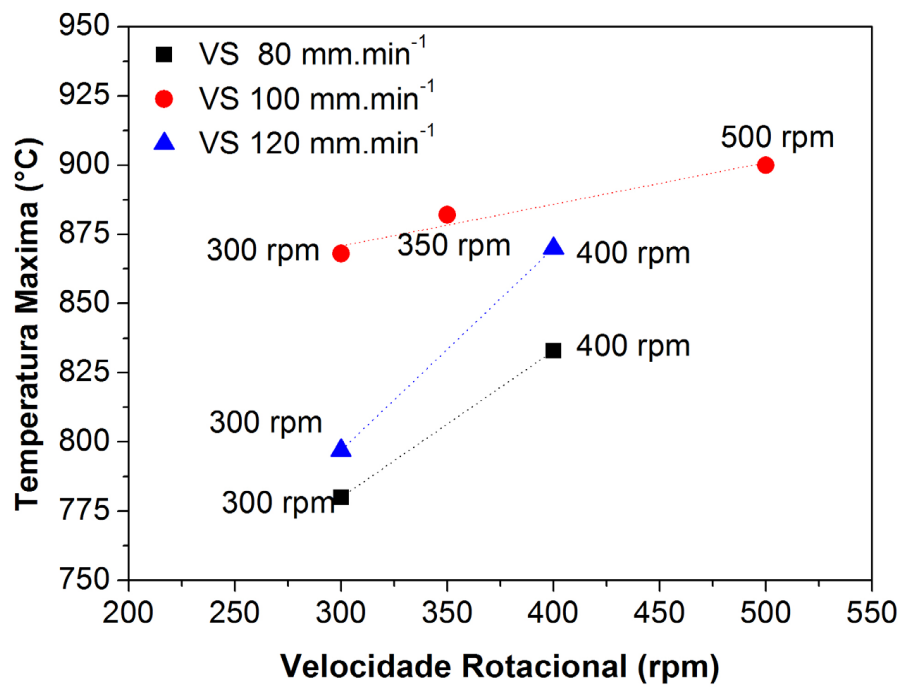

Figura 4. Variação da temperatura máxima na ferramenta com a velocidade rotacional e de soldagem para as juntas soldadas. 
da junta, responsável pela geração de calor necessário (por atrito) para formação da região plástica e retenção desta. Isto porque é necessário que o ombro da ferramenta contenha o fluxo vertical de material e o redirecione para baixo, desempenhando um papel decisivo na produção de juntas sem defeitos e com bom acabamento superficial $[10,11]$. Pela Tabela 4, pode-se verificar que a força axial, a qual determina a penetração da ferramenta no material, é menor para as juntas soldadas com VS de $80 \mathrm{~mm} / \mathrm{min}$.

Pela Figura 5, observa-se que, para uma mesma velocidade de soldagem, o torque é reduzido com o aumento da velocidade de rotação. Este comportamento está associado ao aumento na taxa de geração de calor e consequentemente da temperatura, que reduzindo a tensão cisalhante atuante entre a ferramenta e o material sendo soldado, facilita o escoamento plástico do material. A Figura 4 ilustra bem este comportamento, na qual observa-se que para uma mesma velocidade de soldagem a medida que se eleva a velocidade de rotação, a temperatura máxima na ferramenta aumenta, o que consequentemente ocasiona a redução do torque.

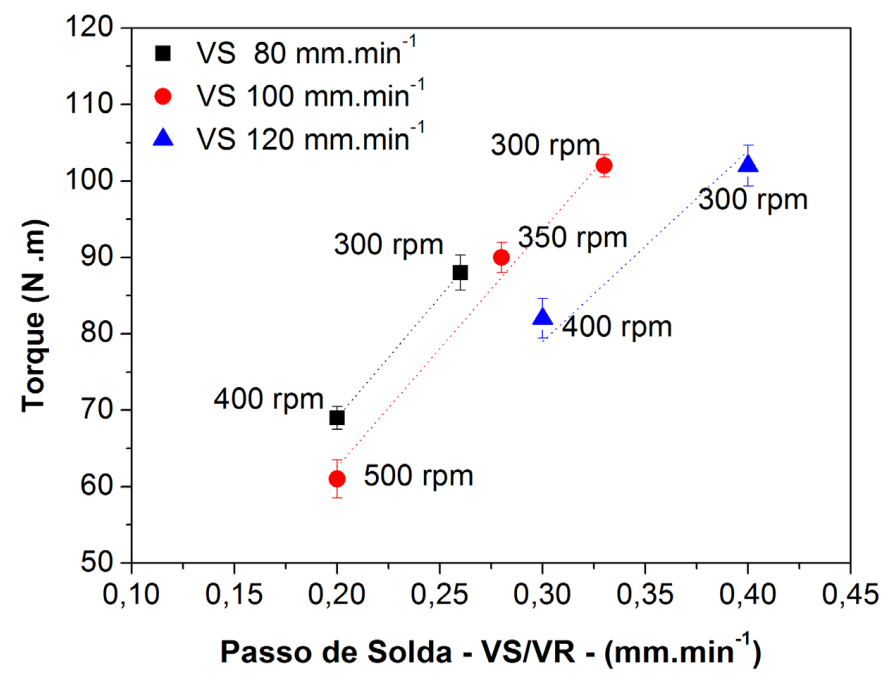

Figura 5. Variação do torque na ferramenta com o passo de solda (VS/VR) para as juntas soldadas.

A Figura 5 também mostra que, mantendo-se a velocidade rotacional constante, (300 e $400 \mathrm{rpm}$ ), há uma tendência do torque aumentar com a elevação da velocidade de soldagem de 80 para $120 \mathrm{~mm} / \mathrm{min}$. De forma diferente, para ligas de alumínio foi observado que o torque não é significativamente afetado por variações na velocidade de soldagem. Isto porque a velocidade relativa entre a ferramenta e o material é influenciada principalmente pela velocidade rotacional, sendo a geração de calor pouco afetada pela velocidade de soldagem [12]. Tal diferença observada se deve ao fato do aço apresentar uma temperatura de fusão superior a do alumínio, fazendo-se assim necessária uma taxa de geração de calor maior para reduzir a tensão cisalhante atuante entre a ferramenta e o material durante o processo de SAPNC.

Nos ensaios preliminares de soldagem foi observado que o equilíbrio entre as forças atuantes durante o processo, depende também da escolha correta da força axial. Sendo que, para um dado conjunto de parâmetros (velocidades de soldagem e rotacional) uma força axial muito elevada, resulta no superaquecimento e alargamento do cordão de solda enquanto que, para uma força axial muito baixa o aquecimento é insuficiente, levando à formação de defeitos volumétricos (vazios) e até mesmo à fratura da ferramenta.

$\mathrm{Na}$ Figura 6 observa-se que a força axial tende a diminuir com o aumento da velocidade rotacional para uma mesma velocidade de soldagem, e a aumentar com a elevação da velocidade de soldagem quando se tem uma mesma velocidade de rotação (300 e $400 \mathrm{rpm}$ ). Veja que este comportamento está de acordo com o observado durante os ensaios preliminares, ou seja, a força axial é reduzida com o aumento da velocidade rotacional para uma mesma velocidade de soldagem visando evitar o superaquecimento e alargamento do cordão de solda, e é aumentada com a elevação da velocidade de soldagem quando se tem uma mesma velocidade de rotação 
Desenvolvimento dos Parâmetros do Processo de Soldagem por Atrito com Pino Não Consumível para o Aço de Alta Resistência e Baixa Liga ISO 3183 X80M

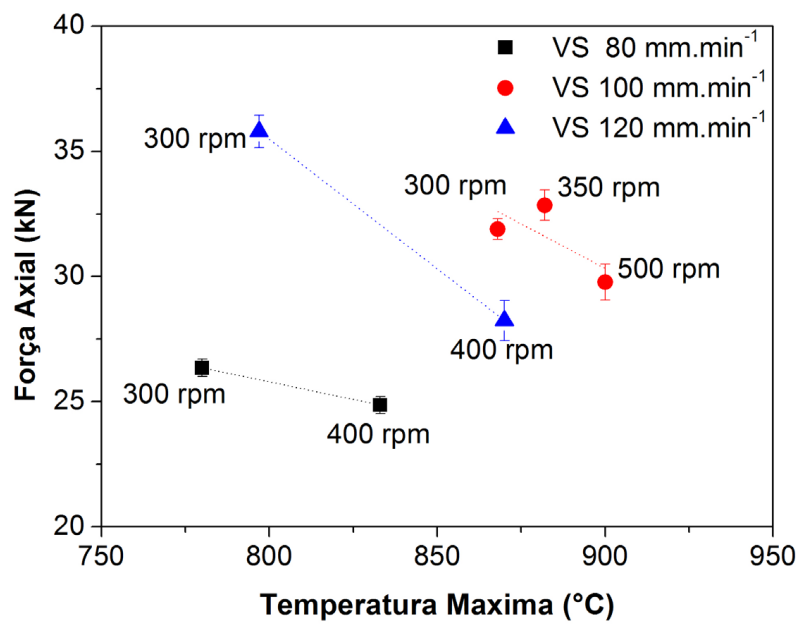

Figura 6. Variação da Força Axial com a temperatura máxima na ferramenta para as juntas soldadas.

(300 e 400 rpm) para aumentar a penetração da ferramenta e com isto, a taxa de geração de calor. Desta maneira, se garante o contato adequado do ombro da ferramenta com a superfície da junta e, assim, promovendo o fluxo adequado do material plastificado, evitando a formação de defeitos volumétricos e a falha da ferramenta.

Pelas Figura 7 e Figura 8, observam-se que, embora a força axial seja um parâmetro de entrada, (estabelecido previamente de acordo com a velocidade de soldagem e de rotação a serem utilizadas), e $F_{x}$ um parâmetro de saída, estas apresentam um mesmo comportamento, tendendo a diminuir sutilmente com a elevação da velocidade de rotação para uma mesma velocidade de soldagem, e a aumentar com a elevação da velocidade de soldagem para uma mesma velocidade de rotação (300 e 400 rpm). Observa-se que neste caso, como era de se esperar, a $F_{x}$ que é a força exercida sobre a ferramenta na direção de soldagem sofre um efeito maior da velocidade de soldagem.

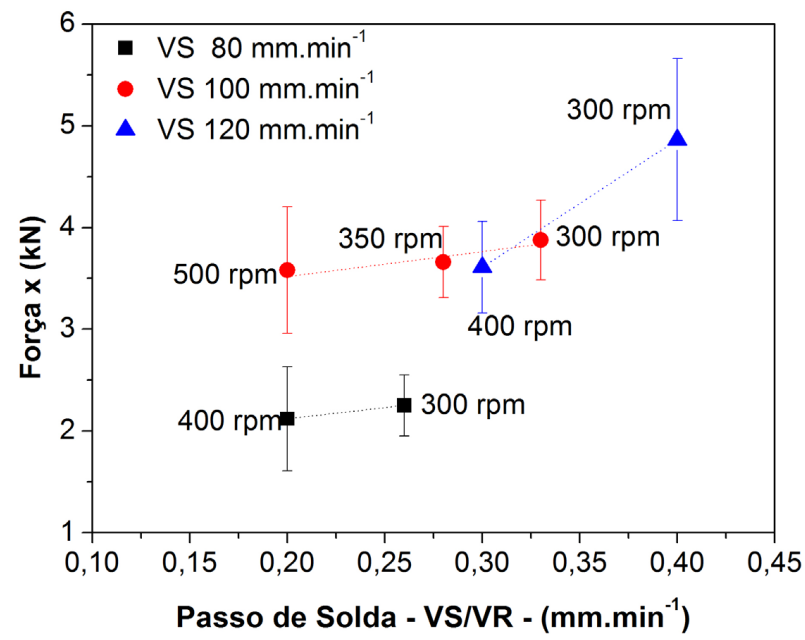

Figura 7. Variação da Força x com o Passo de Solda para as juntas soldadas.

Verifica-se que quanto maior o passo de solda (razão VS/VR), menor é o aporte térmico e maiores são as forças atuantes durante o processo (torque, força na direção $x$, força axial) e sobre a ferramenta, aumentando o seu desgaste e reduzindo, assim, a sua vida útil. Por outro lado, observa-se que quanto menor o passo de solda, menores são as forças atuantes devido ao maior aporte térmico, podendo levar a perda da ferramenta por degradação térmica. 


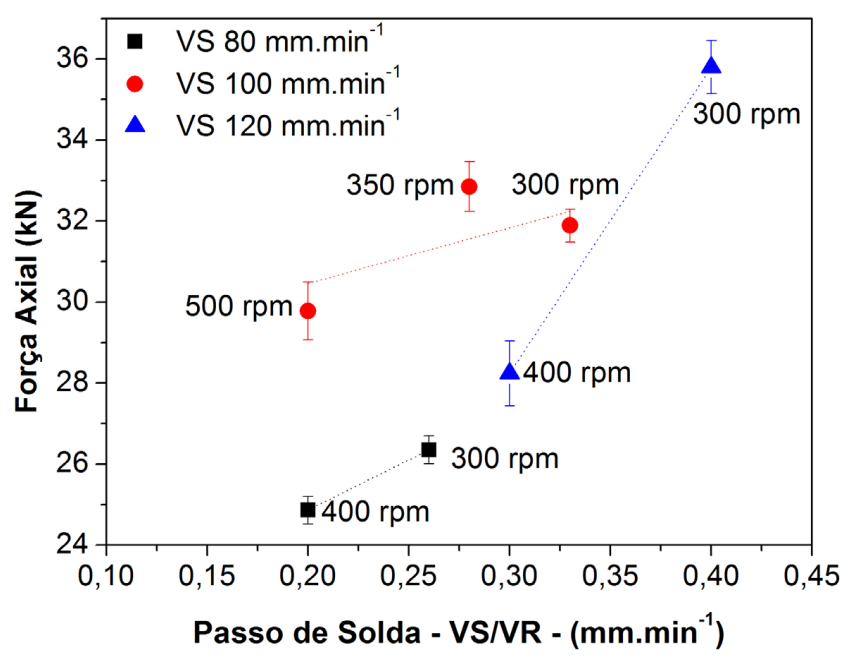

Figura 8. Variação da Força Axial com o Passo de Solda para as juntas soldadas.

Segundo Rai et al. [13], as forças e o torque que atuam sobre a ferramenta durante o processo são importantes por várias razões. Em primeiro lugar, um torque elevado corresponde a uma requisição maior de força para o processo de SAPNC. Em segundo lugar, a deformação da ferramenta e o desgaste são acentuados com o aumento da carga sobre esta, levando a um aumento no custo do processo devido à substituição frequente da ferramenta. E em terceiro lugar, o desgaste da ferramenta pode levar a contaminação da solda e a deterioração das propriedades da junta soldada.

Desta maneira, de acordo com o comportamento observado para aço estudado durante o processo de SAPNC, pode-se inferir que, o parâmetro de soldagem ideal é aquele que requer uma menor força atuante durante o processo, buscando o equilíbrio na taxa de geração de calor a fim de evitar a formação de defeitos e a fratura ou desgaste da ferramenta, seja por excesso ou falta de aporte térmico. A Figura 9, adaptada de Mishra e Mahoney [14], mostra esquematicamente a região ideal para escolha dos parâmetros de soldagem e os defeitos normalmente observados quando se extrapola este limite.

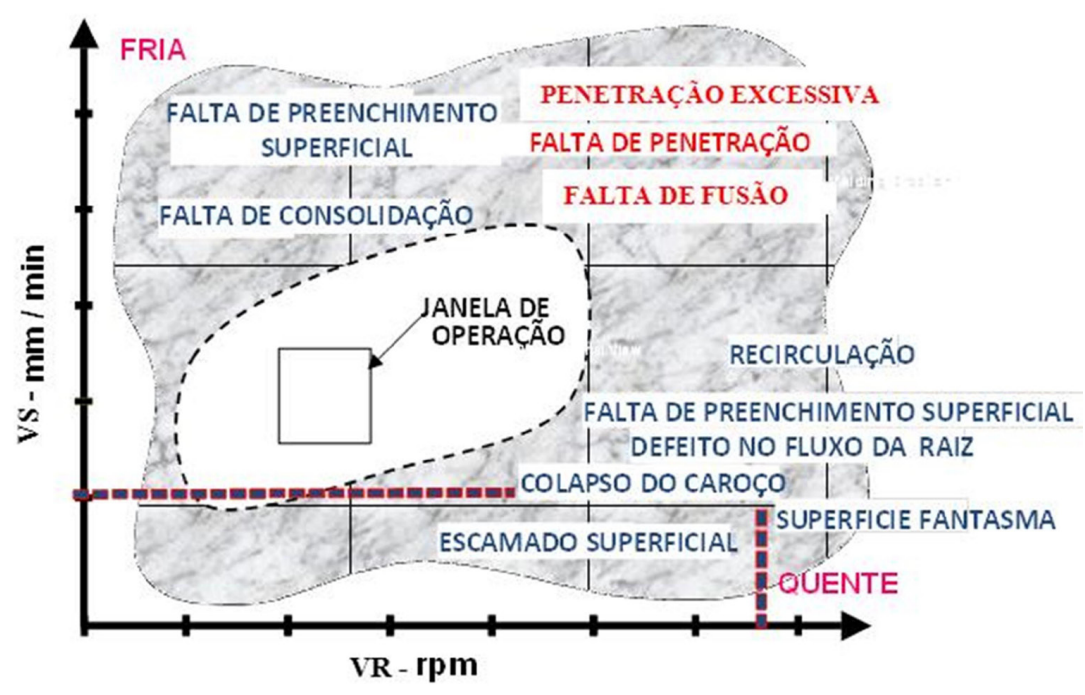

Figura 9. Tipos de defeitos característicos do processo de SAPNC em função da variação dos parâmetros, velocidade de soldagem, VS ( $\mathrm{mm} / \mathrm{min}$ ) e velocidade rotacional, VR (rpm). Adaptada de Mishra e Mahoney [14]. 
Desenvolvimento dos Parâmetros do Processo de Soldagem por Atrito com Pino Não Consumível para o Aço de Alta Resistência e Baixa Liga ISO 3183 X80M

\subsection{Ensaios mecânicos}

Todas as juntas processadas foram radiografadas e avaliadas segundo a norma [10], tendo sido todas aprovadas, não apresentando qualquer tipo de defeito ao longo de toda a extensão.

Nos testes de dobramento lateral e tração todos os parâmetros testados foram aprovados conforme norma. Os corpos de prova de dobramento mostraram-se isentos de descontinuidades e os de tração fraturaram no metal de base, como ilustra a Figura 10, com o limite de resistência superior ao valor mínimo de 621 MPa, requerido por norma, porém inferior ao medido para metal de base, conforme Tabela 2.
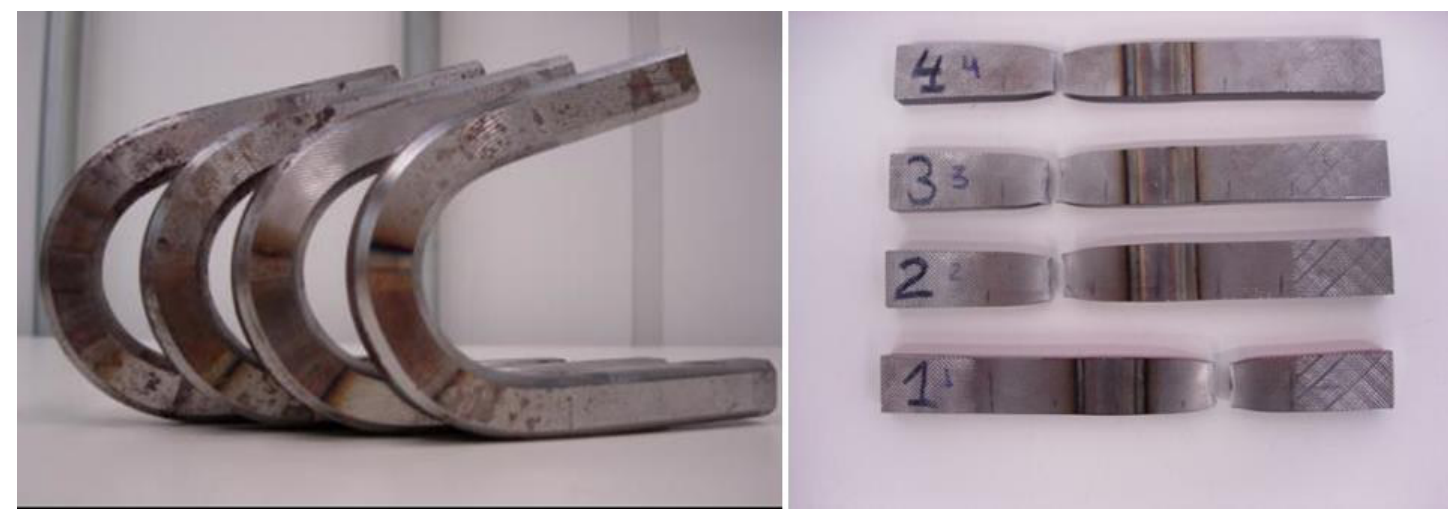

Figura 10. Corpos de prova de dobramento lateral e tração ensaiados segundo a norma ISO 3183.

O rompimento dos corpos de prova de tração no metal de base foi associado à presença preponderante de microestruturas bainíticas (bainita granular, ferrita bainítica), observadas na zona termicamente afetada e na zona misturada, o que elevou a resistência mecânica da junta, favorecendo assim a ruptura dos corpos de prova no metal de base conforme estudo realizado previamente [15].

\section{Conclusões}

É possível a obtenção de juntas soldadas de aço ISO 3183 X80M através do processo de SAPNC atendendo aos requisitos da norma ISO 3183. Porém, para aplicação do processo em escala industrial há ainda algumas limitações com resoluções relativamente simples como, equipamento de soldagem de baixa flexibilidade, não portátil e de elevado custo, furo na peça ao fim da soldagem, e mais complexa como, tempo de vida útil limitado da ferramenta. Desta maneira, no momento o processo é interessante apenas para avaliação do comportamento microestrutural e mecânico do aço, o que virá a auxiliar na determinação do potencial de uso do processo de SAPNC quando a vida operacional da ferramenta for consideravelmente aumentada.

Para um dado conjunto de parâmetros (força axial, velocidade de soldagem e rotacional) mantendo-se a velocidade de soldagem constante, o aumento da velocidade rotacional e /ou da força axial, tende a reduzir as forças e o torque atuantes durante o processo pelo aumento da taxa de geração de calor. O contrário, mantendo-se a velocidade rotacional e a força axial constante, o aumento da velocidade de soldagem tende a aumentar as forças e o torque, uma vez que para o aço, por apresentar uma temperatura de fusão elevada, a velocidade de soldagem desempenha um papel significativo na taxa de geração de calor durante o processo, o que não é observado para materiais com baixa temperatura de fusão, como o alumínio.

A força axial em conjunto com a velocidade rotacional e de soldagem influenciam diretamente nas transformações microestruturais e no desempenho mecânico das juntas soldadas, uma vez que a taxa de geração de calor, e consequentemente de resfriamento são dependentes destas variáveis.

\section{Agradecimentos}

Os autores agradecem o apoio financeiro da Petrobras e FINEP, bolsas de estudo do CNPq e a Tenaris Confab pela doação do aço. TFCH e TFAS agradecem ao LNNanno/CNPEM/MCTI, FACEPE e UFPE. 


\section{Referências}

[1] Gray JM, Pontremoli M. Metallurgical options for API Grade X70 and X80 linepipe. In: Proceedings of the International Conference Pipe Technology; 1987; Rome, Italia. Rome: AIM; 1987.

[2] Bott IS, Souza LFG, Teixeira JCG, Rios PR. High-strength steel development for pipelines: a brazilian perspective. Metallurgical and Materials Transactions A: Physical Metallurgy and Materials Science. 2005;36(2):443-454. http://dx.doi.org/10.1007/s11661005-0315-9.

[3] American Petroleum Institute. API Standard 1104: welding of pipelines and related facilities. 20th ed. Washington: API; 2005.

[4] Thomas WM, Nicholas ED. Friction stir welding for the transportation industries. Materials \& Design. 1997;18(4-6):269-273. http:// dx.doi.org/10.1016/S0261-3069(97)00062-9.

[5] Santos TFA, López EAT, Fonseca EB, Ramirez AJ. Friction stir welding of duplex and superduplex stainless steels and some aspects of microstructural characterization and mechanical performance. Materials Research. 2016;19(1):117-131. http:// dx.doi.org/10.1590/1980-5373-MR-2015-0319.

[6] Russell MJ, Blignault C, Horrex NL, Wiesner CS. Recent developments in the friction stir welding of titanium alloys. Welding in the World. 2008;52(9):12-15. http://dx.doi.org/10.1007/BF03266662.

[7] Hermenegildo TFC. Soldagem por atrito com pino não consumível do aço de alta resistência ISO 3183 X80M [tese de doutorado]. Campinas: Universidade Estadual de Campinas; 2012.

[8] Nandan R, Debroy T, Bhadeshia HKDH. Recent advances in friction-stir welding: process, weldment structure and properties. Progress in Materials Science. 2008;53(6):980-1023. http:// dx.doi.org/10.1016/j.pmatsci.2008.05.001.

[9] International Organization for Standardization. ISO 3183: petroleum and natural gas industries: steel pipe for pipelines: technical delivery conditions. 2. ed. Genebra: ISO; 2007.
[10] Thomas WM, Dolby RE. Friction stir welding developments. In: Proceedings of the 6th International Conference on Trends in Welding Research; 2002; Georgia, USA. Materials Park: ASM International; 2002 [acesso em 22 mar. 2017]. Disponível em: http://www.twi.co.uk/j32k/protected/band_8/spwmtapril2002. html

[11] McClure JC, Coronado E, Aloor S, Nowak BM, Nunes AC Jr. Effect of pin tool shape on metal flow during friction stir welding. In: Proceedings of the 6th International Conference on Trends in Welding Research; 2002; Georgia, USA. Materials Park: ASM International; 2002. p. 257-261.

[12] Peel MJ, Steuwer A, Withers PJ, Dickerson T, Shi Q, Shercliff H. Dissimilar friction stir welds in AA5083-AA6082. Part I: process parameter effects on thermal history and weld properties. Metallurgical and Materials Transactions A: Physical Metallurgy and Materials Science. 2006;37(7):2183-2193. http://dx.doi. org/10.1007/BF02586138.

[13] Rai R, De A, Bhadeshia HKDH, DebRoy T. Review: friction stir welding tools. Science and Technology of Welding and Joining. 2011;16(4):325-342. http://dx.doi.org/10.1179/1362 171811 Y.0000000023.

[14] Mishra RS, Mahoney MW. Friction stir welding and processing. Materials Park: ASM International; 2007. Application of friction stir welding and related technologies; chap. 13, p. 293-295.

[15] Santos TFA, Hermenegildo TFC, Afonso CRM, Marinho RR, Paes MTP, Ramirez AJ. Fracture toughness of ISO 3183 X80M (API $5 \mathrm{~L}$ X80) steel friction stir welds. Engineering Fracture Mechanics. 2010;77(15):2937-2945. http://dx.doi.org/10.1016/j. engfracmech.2010.07.022. 